\title{
“A ECONOMIA DAS TROCAS LINGÜÍSTICAS", DE PIERRE BOURDIEU E “AS CATILINÁRIAS", DE MARCUS TULLIUS CÍCERO: REFLEXÃO SOBRE A APLICABILIDADE DE UMA TEORIA SOCIOLÓGICA A UM TEXTO LATINO.
}

\author{
Janete Melasso Garcia \\ "Quo usque tandem abutere, Catilina, patientia nostra?... \\ O tempora! O mores!... \\ Ad mortem te, Catilina, duci iussu consulis iampridem oportebat;
}

\begin{abstract}
RESUMO: Marcus Tullius Cicero, born 106 B.C., has always been considered the greatest and most competent orator that has ever lived. Pierre Bourdieu, a modern sociologist, has developed a theory about the concept of broadened linguistic competence, stressing the necessary requirements for a speaker to be considered competent from the scientific point of view. The present article deals with the applicability of Bourdieu's sociological theory, entitled: The Economy of Linguistic Exchanges", to a Latin text by Cicero, with a view to confirming the pertinence of the ancient orator's prestige.
\end{abstract}

PALAVRAS-CHAVE: Cícero, Bourdieu, análise do discurso, latim, competência lingüística.

\section{INTRODUÇÃO}

\footnotetext{
Nosso primeiro contato com P. Bourdieu se deu por meio do texto "A economia das trocas lingüísticas".

Como professora de Latim da Universidade de Brasília, ao analisar os discursos de Cícero "As Catilinárias" com os alunos do nível II, impressionou-me fortemente a possibilidade de comprovação da competência discursiva desse autor à luz da teoria sociológica que então examinava.

Foi um processo de reflexão bastante atraente que me levaria a indagar da aplicabilidade de uma teoria sociológica a um texto latino. De fato, o passo seguinte foi o de mergulhar novamente nos dois textos referidos, procurando, numa releitura de Bourdieu, descobrir, até que ponto, Cícero, como orador, poderia ser enquadrado nessa teoria.

Senão, vejamos:

Em 64/ 63 a.C., Cícero, então cônsul, procurava por meio desses seus discursos convencer o Senado Romano a condenar à morte Lucius Sergius Catilina, que também pleiteava a renovação de sua candidatura ao consulado. Sua morte era pedida devido à conspiração anárquica que tramava contra a República.
}

Janete Melasso Garcia é professora do Instituto de Letras da Universidade de Brasília 
Com o primeiro discurso ( 8 de novembro), Cícero frustra o massacre planejado por Catilina e o expulsa da cidade; com o segundo ( 9 de novembro), expõe a situação aos cidadãos e aponta quais são os conspiradores; no terceiro ( 2 e 3 de novembro) explica a evolução dos acontecimentos e finalmente na quarta oração, pronunciada no Senado (5 de dezembro), trata da pena que deveria ser aplicada aos revoltosos.

Várias questões poderiam ser adversas às pretensões do orador, não fossem as estratégias discursivas aplicadas por ele, evidenciando sua competência.

No decorrer destas reflexões, analisaremos essas situações desfavoráveis e os meios discursivos usados pelo autor para contorná-las.

De fato, a história nos comprova que Cícero atingiu seu objetivo com a condenação de Catilina, o que já evidencia sua competência discursiva nos restando apenas a análise dos recursos empregados por ele.

É certo que, quando visamos ao estudo das estratégias discursivas, próprias dos textos políticos, como "As Catilinárias" de Cícero, e enfocando o ato de fala como um evento social, vários aspectos se evidenciam.

Partindo da situação social em si, o primeiro passo seria a configuração dessa mesma situação como um contexto particular com todas as suas regras específicas e daí chegar-se à conclusão de que o ser social agente nesse contexto teria ou não a habilidade necessária para interagir com sucesso, demonstrando possuir o que Bourdieu aponta como sendo a competência ampliada.

Em "A economia das trocas lingüísticas", Bourdieu realmente nos oferece o referencial teórico para fazermos uma análise deste tipo.

Em todos os trabalhos que lemos desse autor, fica patente o uso da terminologia do campo econômico aplicada aos vários campos das ciências sociais. A escolha por tal terminologia poderia ser atribuída não só à influência marxista mas também à profundidade de seus estudos que teriam levado Bourdieu à séria conclusão de que na sociedade humana a relação de poder sempre se baseia no poder econômico: pode mais quem possui mais capital; capital este que depende do mercado a ser considerado.

\section{CAMPO}

Podemos considerar primeiramente a noção de campo, segundo Bourdieu, como um domínio específico de ação social com suas regras bem determinadas e no qual há uma situação, não propriamente de conflito, mas de confronto entre o ser social que atua e seus interagentes.

A intenção do indivíduo numa situação de interação é evidentemente obter êxito naquilo a que se propõe e para tanto deverá primeiramente reconhecer o campo no qual está situado e as regras específicas que o regem.

Analisando o campo em questão, Cícero reconhece o campo político e como orador a situação lingüística que o envolve.

Reconhece ainda a identidade do "habitus" que se estabelece entre ele e seus interagentes. Percebe a própria situação social e os papéis que são atribuídos a si e aos outros.

Sua fala é autorizada, pois é inerente ao cargo político que exerce.

\section{CAPITAL E MERCADO}

Encarando o campo político como um mercado onde se darão as trocas simbólicas feitas por meio de um capital próprio desse campo, teríamos que observar, primeiramente, de que capital Cícero deveria dispor para efetuar suas trocas com seus interagentes.

Ainda consideraríamos o que o orador intentaria trocar, vender, ou impingir a seus pares políticos, entrando aí a análise da intenção de Cícero. 
Sua intenção, como sabemos, era a de levar o Senado Romano a condenar à morte um outro cônsul, Catilina.

Nosso orador considera a estrutura da relação de forças simbólicas na qual não avalia apenas a estrutura das competências propriamente lingüísticas, que consistiria no código lingüístico próprio do campo político com enfoque na oratória. Esse código era o latim culto, falado pelas classes dominantes e no qual Cícero era mestre.

Se, entretanto, a competência lingüística propriamente dita for encarada na visão chomskyana de linguagem gramaticalmente conforme, não será suficiente para um ótimo desempenho numa interação comunicativa.

A competência lingüística deverá, além de gramaticalmente conforme, ser também adequada, ou seja, deveríamos substituir a noção de gramaticalidade por aceitabilidade, quando a linguagem empregada será, então, realmente legítima.

Nesse caso, o código legitimamente empregado poderia ser considerado como capital válido para o mercado em questão.

É o que poderíamos considerar como linguagem adequada ou linguagem legítima ou ainda o capital simbólico apropriado ao campo considerado.

\section{A COMPETÊNCIA LINGÜÍSTICA AMPLIADA}

Bourdieu nos fala da competência lingüística ampliada como sendo um conjunto de propriedades que o falante deve possuir para interagir com êxito.

Quando Cícero se dirige a seus pares no Senado Romano, usando como código comum a eles a língua latina no registro culto, demonstra sua competência lingüística como parte de seu capital simbólico, entretanto nos patenteia sua competência ampliada quando, entre outras estratégias, emprega:

a) os pronomes pessoais no singular para determinar seu envolvimento ou não nos fatos apontados;

b) os pronomes pessoais no plural (para uma ação que é sua) para criar um sentimento de conivência e participação com seus interagentes;

c) o valor modal do Indicativo (fato real) para dar cunho de veracidade aos fatos relatados;

d) o valor modal do Subjuntivo (fato irreal ou apenas potencial) para não apresentar as questões como certas.

Dessa maneira sua linguagem não se apresenta apenas como correta, mas também como adequada.

\section{HABITUS}

É em sua argumentação suasória que percebemos outro elemento importante do capital simbólico do orador que vai demonstrar sua competência ampliada: o conhecimento do habitus dos ouvintes e o reconhecimento do seu próprio.

Segundo Bourdieu, o habitus é a própria formação cultural dos indivíduos. Primeiramente no ambiente familiar e posteriormente com a vivência social, o indivíduo adquire conceitos, crenças, expectativas e posicionamentos diante da vida, que nortearão suas atitudes.

Essa visão coincide com a teoria cultural dos etnometodologistas.

Senão vejamos:

Cícero pedia ao Senado que punisse com a morte um de seus pares: Catilina.

Conhecendo o habitus do povo romano, nosso orador sabia o quão avessos a novidades políticas e sociais eram eles, conhecia o quanto eram apegados às tradições ancestrais, além de perceber, numa análise psicológica da solidariedade de grupo, quantos obstáculos encontraria a suas pretensões. É quando rememora aos senadores, patres conscripti, fatos da tradição histórica romana, descrevendo situações idênticas à que 
propunha: outros políticos influentes também já tinham sido condenados à morte ( mors ac poena reipublicae) em situações semelhantes.

Com isso, retirava também de seus ouvintes a responsabilidade da tomada de decisão, da abertura de um precedente, num assunto novo, evidenciando seu conhecimento do habitus romano.

Ainda, numa análise da psicologia individual, Cícero, percebendo que sensibilizaria os senadores aos seus propósitos, tocando-os quanto a sua segurança pessoal, fá-los perceber que Catilina indica cada um a seus asseclas, com os olhos, como possíveis vítimas de massacre.

Essa sensibilidade aos signos da percepção que determina a sua produção lingüística faz parte também de seu capital, corroborando assim para que sua competência ampliada se evidencie.

Não apontando diretamente os senadores que simpatizavam com Catilina, mas apenas indicando posturas gerais que levariam a essas conclusões, Cícero faz uso adequado da censura, configurando-se na estrutura do seu campo de ação. E assim dava a oportunidade de que alguns de seus opositores, temerosos de represália, mudassem seus votos.

Realmente, no emprego de suas estratégias discursivas vemos claramente como nosso orador compreendia bem a formação dos preços nesse mercado de trocas simbólicas e antecipava seus lucros à medida que percebia a adesão dos interagentes a sua intenção.

Uma outra questão, muito importante na oratória, é a do uso corporal, como estratégia de convencimento. Na verdade, não possuímos elementos objetivos para comprovar essa estratégia através dos textos discursivos de Cícero, mas quando ele emprega os pronomes demonstrativos hic (este), iste (esse), por exemplo, parece-nos que seu braço se erguia apontando e sua cabeça se voltava para aquele a quem lingüisticamente se dirigia.

Tanto assim deve ter sido, que quando foi assassinado, tendo sua cabeça e mãos decepadas, estas foram expostas no púlpito ( rostrum) de onde costumava proferir seus discursos, como demonstração do escárnio de seus inimigos pelas "armas" de Cícero: sua inteligência e sua gestualização. Dizem alguns que sua língua foi presa por um cravo para, simbolicamente, paralisar a mais terrível de suas armas.

Não podemos deixar de julgar essa atitude como um reconhecimento dos inimigos de Cícero de que ele foi extremamente competente e que "suas armas" eram para eles o indício dos perigos que acarretaram com seu uso.

\section{O DISCURSO POLÍTICO}

No discurso político, mais precisamente na oratória, a evidência maior é dada ao falante que antes de mais nada deve ter a consciência do papel que desempenha nesta interação comunicativa e, mais ainda, do papel que o ouvinte assume.

Na prática do discurso oratório, a atuação dos ouvintes é passiva no sentido da participação efetiva no ato de fala. Eles ouvem porque reconhecem no orador a linguagem autorizada. À primeira vista, nos parece uma via de mão única, pois apenas um se pronuncia sobre determinado referente e os outros apenas recebem a mensagem através de um código comum a ambos.

Na verdade esta unilateralidade é apenas aparente, pois se a intenção do falante é a de não somente expor, mas num processo de "engagement", persuadir aos ouvintes a adotarem seu ponto de vista em relação ao referente, de certa forma a atuação dos ouvintes será no sentido de monitorar psicologicamente o comportamento do falante.

E para que este tenha êxito, é necessário que possua a competência lingüística ampliada que Bourdieu nos aponta e que analisamos até aqui.

\section{P. BOURDIEU E M. PÊCHEUX}


Ao analisarmos a teoria sociológica de Bourdieu, notamos certo paralelismo com a teoria sociolingüística que M. Pêcheux (apud Osabake,'79) nos apresenta, num esquema dos componentes fundamentais da interação comunicativa.

Pêcheux primeiramente considera o destinador (A) e o destinatário (B), o referente (R) e o código comum a (A) e (B), para em seguida propor as seguintes questões:

1. Quem é (A) para falar assim a (B) ?

2. Quem é (B) para que (A) lhe fale assim ?

3. De que ( $R$ ) (A) fala a (B)?

4. O que (A) pretende falando assim a (B) ?

5. Com que autoridade (A) fala deste assunto ( $\mathrm{R}$ ) e por esta forma a (B) ?

Para que (A) tenha sucesso ou possa ser considerado portador da competência lingüística ampliada, a que se refere Bourdieu, deverá procurar o estabelecimento dos papéis dos interlocutores na interação comunicativa, tentando com isso desfazer as possíveis assimetrias que poderão existir entre (A) e (B), como estratégia de persuasão.

Retomando Pêcheux, (A) deverá estar apto a responder as questões:

1. Do ponto de vista lingüístico, o código usado é comum a (A) e (B) ?

2. Qual a imagem que (A) faz de (B) para lhe falar dessa forma ?

3. Qual a imagem que (B) tem de (A) para que (A) lhe fale dessa forma?

4. Que imagem (A) tem do ( R ) para falar a (B) dessa forma ?

5. Que imagem (A) pensa que (B) faz do ( R ) para que (A) fale dessa forma a (B)?

6. O que (A) pretende de (B) falando-lhe assim ?

\section{CONCLUSÃO}

Em nosso caso específico:

- Cícero (A) dirige-se aos senadores romanos (B);

- ( $R$ ) é a punição que Cícero pede para Catilina;

- o código comum a (A) e (B) é a língua latina no registro culto.

As outras questões são respondidas pelas estratégias empregadas por (A), como o conhecimento do habitus de (A) e (B); o reconhecimento do campo da ação social em questão; a linguagem autorizada, o tipo de capital usado dentro do mercado específico, etc.

A teoria sociológica de Bourdieu vem ao encontro das tendências mais modernas da lingüística, mais propriamente da sociologia interacional que se situa num espectro bastante amplo, não só quando focaliza as questões lingüísticas estruturais, mas na medida em que se preocupa com o falante, o ouvinte, o referente e o código usado e passa a imbricar em sua proposta não só as ciências sociais mas até mesmo a lógica matemática.

Com as novas posturas em reformular as categorias básicas do estudo lingüístico a partir do enfoque social, como já fez Hymes ('74), surge uma convergência da sociolingüística com a lógica pragmática na análise empírica da interação verbal.

De fato, a ênfase, hoje em dia, é dada à pragmática da linguagem. Lavandera ('85), encara a tarefa do lingüísta moderno como extremamente complexa, pois dele se espera que saiba manejar todo o background lingüístico, explorado em todas as fases anteriores da pesquisa.

É uma grande responsabilidade, desde que se proponha a fazer uma análise total do ato de fala.

Podemos assim concluir que o próprio pesquisador deverá também, segundo Bourdieu, apresentar uma competência ampliada dentro de seu campo de ação para que possa auferir lucros neste intrincado mercado de trocas simbólicas. 


\section{BIBLIOGRAFIA}

BAKTIN, Mikhail. Marxismo e filosofia da linguagem. São Paulo, Hucitec, 1986.

BORTONI, Stella Maris. Linguagem e sexismo: o uso da gíria. In: Anais do V Encontro Nacional de Lingüística. Rio de Janeiro, Div. de Interc. e edições, out. 1981.

BOURDIEU, Pierre. Sociologia. São Paulo, Ática, 1983.

CICERON. Discours - Tome X - Catilinairies. Par H. Bornecque et E. Bailly. Paris, Belles Lettres, s.d.

HAMEL, Riner E. Constituicion y análisis de la interacion verbal. In: Estudios de lingüística aplicada. México, CELEx, UNAM, 1982.

. Analisis conversacional. In: Estudios de lingüística aplicada. México, CELEx, UNAM, 1984.

JAKOBSON, Roman. Lingüística e comunicação. 12 ed. São Paulo, Cultrix, 1985.

KOCH, Ingedore; VILLAÇA, G. Argumentação e linguagem. São Paulo, Cortez, 1984.

LAVANDERA, Beatriz R. Curso de lingüística para el analisis del discurso. Buenos Aires, Centro Edit. de A. Latina, 1985.

MARCONDES DE S. FILHO, Danilo. Filosofia, linguagem e comunicação. São Paulo, Cortez, 1953.

ORLANDI, Eni P. A linguagem e seu funcionamento. São Paulo, Pontes, 1987.

OSABAKE, Haquira. Argumentação e discurso político. São Paulo, Kairós, 1979. 